\title{
Abuso SeXual: do QUe SE TRATA? ContribuiçốES DA PSICANÁLISE À ESCUTA DO SUJEITO ${ }^{I}$
}

\author{
Pedro Moacyr Chagas Brandão Junior* \\ Patrício Lemos Ramo***
}

\section{Resumo}

O artigo é parte da Dissertação de Mestrado "O sujeito abusado da psicanálise”. A partir de uma revisão crítica da bibliografia sobre o tema do abuso sexual, enfatiza a questão do manejo psicanalítico nesses casos e pretende sustentar um diálogo da psicanálise com outros campos de saber, diferenciando a proposta psicanalítica das demais abordagens encontradas na literatura. A tendência contemporânea de normalização e patologização dos casos é outro ponto de questionamento. Tendo como premissa que o manejo clínico não se define previamente à escuta do sujeito, sem levar em conta sua responsabilidade pelo que lhe ocorreu, verificamos que, muitas vezes, em nome de uma "cientificidade" e do "bem-estar" da criança, corre-se o risco de reforçar uma dimensão policial, de vigilância administrativa, e deixar de lado a implicação subjetiva de cada um.

Palavras-chave: abuso sexual, psicanálise, psicologia da criança.

\begin{abstract}
Sexual abuse: Which treatment? Contributions of PSychoanalysis to THE LISTENING OF THE SUBJECT

The article is part of the Master's degree Dissertation "The abused subject of psychoanalysis". From a critical review of the literature on the topic of sexual abuse, it poses questions regarding the psychoanalytic management of these cases, and intends to support a dialog be-
\end{abstract}

* Mestre em Psicanálise pela Universidade do Estado do Rio de Janeiro (UERJ); Professor da Universidade Iguaçu (UNIG) nos cursos de enfermagem, fisioterapia e farmácia.

** Psicólogo com Especialização em Psicologia Clínica pela Pontifícia Universidade Católica do Rio de Janeiro (PUC-Rio); Psicólogo do programa de Saúde Mental de Muqui (ES); Supervisor Clínico Institucional do Programa de Saúde Mental de Nova Iguaçu (RJ). 
tween psychoanalysis and other fields of knowledge, distinguishing the psychoanalytic proposal from other approaches found in the literature. The contemporary trend of normalization and pathologisation of sexual abuse cases is another point of questioning. Our premise is that the clinical management is not defined previously to the listening of the subject, without taking into account his responsibility for what happened. In many cases, in the name of "science" and "child welfare", we can reinforce a police dimension, of administrative vigilance, setting aside the subjective implication of the individual.

Keywords: sexual abuse, psychoanalysis, child psychology.

\section{INTRODUÇÃO}

As denúncias e notificações de casos de abuso sexual no Brasil são cada vez mais frequentes e com elas aumenta também a demanda por profissionais das áreas da psicologia e psicanálise, seja para avaliação, tratamento ou suporte às equipes de assistência voltadas para esta clientela. Ao mesmo tempo, ainda, aumenta o interesse sobre o abuso sexual, seja em níveis legislativo, acadêmico, ou sociocultural ${ }^{2}$. Um exemplo disso é verificado pela iniciativa da $2^{a}$ Vara da Infância e da Juventude de Porto Alegre, denominada de Depoimento sem Danos, que tenta desenvolver técnicas, questionáveis, ditas mais eficientes, de interrogatório de menores vítimas de violência ou abuso sexual.

Segundo um artigo que propõe uma revisão dos últimos 100 anos de literatura sobre o abuso sexual, no Brasil os "abusos contra crianças e adolescentes somente passaram a ser assunto de estudo e pesquisa há cerca de 45 anos” (Aded, Dalcin, Moraes \& Cavalcanti, 2006: 206). A partir dos anos 80 surgem as campanhas internacionais de sensibilização à violência familiar, "em especial a violência sexual incestuosa, atingindo as escolas, hospitais e tribunais que passaram a ter informaçōes sobre o segredo do incesto" (Barbosa, 2004: 57).

Hoje, verificamos a pregnância de um determinado modelo de atendimento construído ao longo do tempo e que repete, sem questionamento, as tentativas de adequação e normatização da infância, do sexo e das relações entre os adultos e as crianças. Nosso objetivo é oferecer, tendo como base as obras de Freud e Lacan, uma abordagem do abuso sexual que considera a divisão da criança pelo desejo, tornando-a sujeito (até mesmo de seu sofrimento) e fazendo contraponto à ingenuidade e à incapacidade (plenas) atribuídas aos menores, crianças ou adolescentes, atribuição que é comum em algumas práticas de assistência e argumentações teóricas atuais. 
Inicialmente, tomaremos em análise algumas definições e condutas técnicas referentes ao abuso sexual feitas por autores contemporâneos, bem como trechos da legislação nacional que contemplam o tema em discussão. Em seguida, apresentamos a definição de sujeito - introduzido na psicanálise por Jacques Lacan - para então apreciarmos os desdobramentos deste conceito no tocante ao tema em questão, sobretudo naquilo que concerne ao acolhimento do sujeito-criança vítima de abuso sexual.

Por fim, cumpre ressaltar que a psicanálise nasce como um campo do saber que subverte os métodos empregados pela ciência da época, propondo uma nova lógica de operar e, consequentemente, um novo manejo clínico. Freud decide utilizar um método de escuta que difere e questiona as práticas médicas de sua época. Deste modo, consideramos que está incorporado à prática da psicanálise questionar concepções que paralisam e domesticam sujeitos.

\section{Discussão}

Atualmente, observamos em diversas abordagens que a criança vem sendo tomada como um ser incapaz e sem discernimento, sobretudo frente ao abusador. $\mathrm{O}$ adulto, individuo maduro sexualmente, portanto hábil para distinguir as consequências de seus atos, diante desta imaturidade da criança, a toma como um objeto capaz de satisfazer seus desejos. É o que vemos em Amazarray e Koller (1998) ao afirmarem que "o abuso sexual pode ser definido como o envolvimento de crianças e adolescentes em atividades sexuais que não compreendem em sua totalidade e com as quais não estão aptos a concordar" (Amazarray \& Koller, 1998: 561). Junqueira (1999) enfatiza a vulnerabilidade da criança ao defender que o abuso sexual seria uma "tentativa de anulação do sujeito por atacar sua vulnerabilidade [...] a criança abusada sexualmente deixa de ser sujeito e passa a ser submetida” (Junqueira, 1999: 57).

Neste contexto, a criança, este objeto submetido aos desejos de um outro adulto, remete-nos à articulação sexualidade-desamparo. Goldfeder (2001) apontará que nesse momento a criança é confrontada com $o$ excesso e é este excesso que a remete à experiência de desamparo, "marca de suas experiências mais primitivas" (Goldfeder, 2001: 19). Seguindo esta premissa, no ato sexual com o adulto a criança seria objeto e não sujeito.

Podemos ainda relacionar esta concepção àquela apresentada no Plano Nacional de Promoção, Proteção e Defesa do Direito de Crianças e Adolescentes à Convivência Familiar e Comunitária (Brasil, 2006) em que se lê que "a criança e o adolescente 
são sujeitos de direitos [...], indivíduos autônomos e íntegros, dotados de personalidade e vontade próprias". Há, entretanto, a alegação de que ao se relacionar com um adulto a criança ou o adolescente guarda também a mesma posição de vulnerabilidade e submissão de que vimos tratando. É o que salienta Cirino (2001): “assim, a criança tem direitos, mas não pode exercê-los diretamente, devendo ser representada pelos adultos - pais, tutores - aos quais pertencem a competência e o dever de protegê-la" (Cirino, 2001: 39).

Deste modo, a palavra sujeito, naquele documento, é mais um sinônimo de individuo portador de uma interioridade do que exatamente um sujeito - como o entendemos a partir da psicanálise (descreveremos adiante tal concepção). Cumpre salientar que esta concepção que criticamos traz consigo o risco de ela poder dar lugar a práticas em que se permite a um outro expor pela ou sobre a criança e não que esta possa, ela mesma, dizer aquilo que verdadeiramente a incomoda. Após apresentarmos uma forte tendência contemporânea em aproximar a infância à falta de recursos ou preparo, passemos agora às consideraçōes da psicanálise para que, partindo delas, possamos verificar quais são as possíveis contribuições sobre o tema em consideração.

\section{A PROPOSTA DA PSICANÁlISE}

A psicanálise traz a noção de uma criança que também é sujeito, que difere da concepção de indivíduo. Para a psicanálise, "o sujeito como tal, funcionando como sujeito, é algo diferente de um organismo que se adapta [...]. O sujeito está descentrado com relação ao indivíduo" (Lacan, [1954-1955] 1985: 16), é o que escapa à rede de significantes. A advertência de Lacan (1976) é muito clara quanto a isso: não se trata de "méconnâitre minha subjetividade" (Lacan, 1976: 199), mas de um pensar que está vedado à consciência, "trata-se de um pensar em palavras, com pensamentos que burlam nossa vigilância, nosso estado de alerta" (Lacan, 1976: 201).

Apesar de usar o mesmo termo - sujeito -, as duas abordagens dão sentidos diferentes a este. Se falarmos do sujeito como um indivíduo, a direção do tratamento será de que este se torne um ser cada vez mais autônomo, capaz de controlar seus impulsos para viver em sociedade de forma mais adequada, como podemos verificar na seguinte afirmação: "o trabalho com a criança busca viabilizar a reconstrução de seu mundo interior a fim de que ela possa retomar sua vida” (Magalhães, 2005: 68). Para a psicanálise, por outro lado, esse indivíduo está do lado da consciência e há um funcionamento independente desta, inconsciente, que insiste em se mostrar, 
apesar de apenas termos notícias sobre ele a partir da própria consciência e daquilo que o sujeito pode falar de si.

O sujeito é marcado pelos significantes oferecidos pelo Outro, e somente num só depois é que dará sentido a esse encontro. É "um ato de resposta, uma resposta dada em ato" (Elia, 2004a: 41) aos significantes introduzidos pelo Outro no corpo do bebê. Portanto, não pode ser localizado no sentido. É no a posteriori que o sujeito dará significação aos significantes que o marcaram, de modo que não é convocado no que enuncia sobre si, sua subjetividade, mas a partir do furo no sentido que dá às suas marcas.

A partir deste ponto, podemos dizer que, na verdade, o que interessa a um analista não se resume ao que o sujeito pode falar sobre si, ao sentido que dá a seus atos e desejos, mas àquilo que lhe escapa e que se apresenta nos tropeços de sua fala, na hiância entre o que diz e o que quis dizer. Em 2004, Elia afirmará, a partir de Lacan, que o sujeito é um efeito do significante, é sujeito do inconsciente; não nasce nem se desenvolve, não é somático ou orgânico, é "interlegível, ou seja, pode ser lido nas entrelinhas de sua fala, o que faz com que seja inteligível, desde que se estabeleça um dispositivo para isso" (Elia, 2004b: 13).

Outro autor (Cirino, 2001) ressalta que alguns teóricos vão propor

a existência de um estágio final do desenvolvimento psicossexual - momento no qual o sujeito chega a uma relação "madura" com o objeto, o estádio genital ou do amor objetal. Acredita-se no "encontro" entre o sujeito e o objeto, sujeito que se confunde com o eu e objeto que é definido, antes de mais nada, como de satisfação (Cirino, 2001: 96).

No que tange a nosso tema em discussão, o abuso sexual, no momento em que é proposto o efeito traumático do abuso, ou melhor, no exato momento em que se o nomeia de abuso, corre-se o risco de abolir o sujeito, pois se coloca previamente um lugar para este. Consequentemente, o que fica em primeiro plano é o eixo vítima-agressor, remetendo-nos à esfera da culpabilização. Ora, a psicanálise nos defronta com algo que diz respeito a uma responsabilização, a qual não se confunde com a ideia da responsabilização jurídica, no sentido de que "pode haver algum proveito por parte daqueles considerados explorados. $\mathrm{Ou}$, ao menos, não podemos considerá-los totalmente sem responsabilidade" (Ribeiro \& Gryner, 2003: 75).

Para os profissionais, em termos jurídicos, só há uma resposta frente a esses casos: a denúncia/notificação. O Estatuto da Criança e do Adolescente (ECA), lei 8.069 de 13 de julho de 1990 (Brasil, [1990] 2005), regulamenta o artigo 227 da 
Constituição Federal (Brasil, [1988] 1999) que, baseado na doutrina da proteção integral, estabelece, respectivamente nos artigos 13, 130 e 245, que

Art. 13 - os casos de suspeita ou confirmação de maus-tratos contra criança ou adolescente serão obrigatoriamente comunicados ao Conselho Tutelar da respectiva localidade, sem prejuízo de outras providências legais (p. 15).

Art. 130 - Verificada a hipótese de maus-tratos, opressão ou abuso sexual impostos pelos pais ou responsável, a autoridade judiciária poderá determinar, como medida cautelar, o afastamento do agressor da moradia comum (p. 35).

Art. 245 - Deixar o médico, professor ou responsável por estabelecimento de atenção à saúde e de ensino fundamental, pré-escola ou creche, de comunicar à autoridade competente os casos de que tenha conhecimento, envolvendo suspeita ou confirmação de maus-tratos contra criança ou adolescente: Pena - multa de três a vinte salários de referência, aplicando-se o dobro em caso de reincidência (p. 56).

Ressaltamos que não estamos tomando uma posição contrária à denúncia dos casos, ou visamos desculpabilizar o abusador; tampouco ignoramos que há uma preocupação dos órgãos competentes em qualificar os profissionais para a notificação ${ }^{3}$. No entanto, alertamos que deve haver certa cautela na abordagem desses casos.

Cromberg (2001) assegura que "muitas vezes, com a denúncia, há piora do estado psíquico" (Cromberg, 2001: 148) do menor envolvido. Faz essa afirmação a partir de um caso em que a paciente, aparentemente, "piorou com a denúncia", pois percebe que havia uma implicação desta paciente na relação de extrema violência física que ela mantinha com o pai - que, inclusive, chega a arrancar seus dentes com um alicate. Em tratamento, a paciente pôde dizer que, ao mesmo tempo que fugia do pai, também o procurava, inclusive visitando-o na casa da avó. Nesse caso, a denúncia provocou um grande "barulho" na família (significante usado pela paciente) e, segundo a autora, tanto barulho atrapalhava a menor "a elaborar as várias facetas do que aconteceu" (Cromberg, 2001: 94).

Cumpre-nos salientar que estamos defendendo a norma social segundo a qual o suspeito de abuso ou violência infligidos sobre um menor deve ser notificado. Mas nossa presente proposta não se resume a este tipo de crítica, amplia-se à escuta clínica, pois não se pode esquecer que "o furor condenatório da norma penal é composto do mesmo material da transgressão" (Cromberg, 2001: 153), para nos valermos da mesma autora. 
A psicanálise, com seu método e manejo clínico próprios, pode nos dar aparatos para considerar aquilo que o sujeito diz, além de ter como princípio que o sujeito está exatamente lá, naquilo que diz, sem saber o que está dizendo. Fazendo uma aproximação ao nosso tema: se um caso chega para atendimento e o colocamos em uma série predeterminada de acontecimentos, situando-o como um caso de abuso sexual, por exemplo, verificamos o lugar do paciente na família, denunciamos o caso e acreditamos que necessariamente aquela pessoa terá prejuízos em sua vida futura: não deixamos, pois, espaço para que o sujeito advenha. Os casos são patologizados e transformam-se em objeto de pesquisa.

Neste ponto, propomos uma pequena digressão em nosso objetivo principal para voltarmos nossa atenção para esse momento da denúncia e, com ele, observar como a psicanálise pode contribuir também nesta situação. Acreditamos que deve haver um momento em que essa denúncia possa ser feita sem que se incorra no risco de que seja tomada ou identificada a uma nova violência para com o sujeito. Para tal, sugerimos a clínica como balizadora de tal momento. Pois é na clínica, ou partindo dela, que o técnico poderá pensar e avaliar o lugar que esta denúncia ocupará para aquele sujeito que sofreu a violência, o abuso. Será o lugar de introdução da lei, a lei que o pai não pôde fazer operar? Ou será de um barulho estrondoso que o impede de prosseguir? Ou terá a função de negar ou reafirmar sua implicação no caso? Respostas apenas alcançadas nas particularidades dos casos.

Nossa direção é a de que as condutas adotadas pelos técnicos da saúde não sejam feitas por preceitos morais ou por suas próprias inquietações. Que o manejo não seja definido previamente à escuta do sujeito, sem levar em conta sua responsabilidade (e não culpa) pelo que lhe ocorreu. Propomos, com Costa-Moura (2003) ao falar da clínica psicanalítica, que nesta, "portanto, o que se busca não é restituir a criança como ideal perfeito dos pais e adultos que demandam por ela, mas sim uma possível realização do sujeito a partir da problemática do desejo, em toda a sua complexidade" (Costa-Moura, 2003: 130). Quando damos lugares predeterminados aos integrantes da cena, acabamos excluindo o sujeito que, fixado no lugar de vítima, não poderá aparecer como outra coisa.

Há implicação de desejo nos casos de abuso sexual não só por parte do adulto, mas também das crianças, e isso não significa que elas tenham que deslizar para a outra extremidade do eixo vítima-agressor e tornarem-se as sedutoras, ou criminosas. Observa-se que, na maioria das vezes, há um jogo de sedução no qual ambas as partes estão envolvidas, o que ratifica a implicação destas no ato do abuso.

Calligaris (1999), em um texto intitulado "A moral e o abuso sexual infantil", denuncia a resposta da comunidade científica e da população em geral diante de um estudo publicado em 1998, pelo Psychological Bulletin, órgão oficial da American 
Psychological Association. Nesse estudo, três psicólogos (B. Rind, P. Tromovitch e $\mathrm{R}$. Bauserman), através de entrevistas com estudantes universitários, debatiam que o abuso sexual na infância não necessariamente traria danos graves e duradouros à vida das pessoas, o que causou grande estardalhaço e acusaçóes ao estudo. Um grupo de pesquisadores se prontificou a escrever artigos atacando os achados e escrever cartas para o editorial da revista criticando a aprovação da publicação do artigo.

No texto, Calligaris (1999) questiona a posição moral diante desses resultados. Para esse autor "os censores se indignam porque [...] receiam que, se o abuso sexual não for danoso, será difícil provar que é errado" (Calligaris, 1999: 81). Nesse pequeno texto o autor ilustra com perfeição a posição de algumas abordagens que se propõem estudar o tema do abuso sexual nas quais "patológico" e "danos morais" aparecem intimamente conectados. O autor nos alerta que "nem tudo que é errado moralmente é nocivo ou patógeno. E, reciprocamente, nem tudo que é patógeno é necessariamente errado moralmente" (Calligaris, 1999: 81).

Esse fato nos coloca diante de um nó no qual moral e patológico se confundem. Separar esses dois campos é um desafio, já que em suas origens um servia ao outro. Pois é em nome do controle social que, a partir do século XVIII, a medicina (psiquiatria), a pedagogia e a justiça penal, para organizar a sexualidade, acabam por normatizar - da infância à velhice - os comportamentos sexuais, apontando seus possíveis desvios e consequências. É nesse período que localizamos o surgimento de uma ciência sexual, que define a sexualidade e seus processos patológicos (Foucault, [1976] 1998). Há, portanto, uma evolução histórica da posição adotada pelo social frente às relações entre adultos, ou pessoas mais velhas, com as crianças, o que torna necessária uma breve apresentação dessas modificações ocorridas ao longo dos tempos.

\section{A eXClusão do SUJeito E dA HISTÓRIA}

Sabe-se, com Foucault ([1976] 1998), que em um determinado momento da história as experiências sexuais, até então vividas de maneira indiscriminada entre os adultos e os mais jovens desde a antiguidade, passam a ser consideradas como abuso sexual. Este autor relata o caso de um trabalhador agrícola que, em 1866, foi denunciado por obter carícias sexuais de uma menina, "como já havia feito, como tinha visto fazer, como faziam em volta dele os moleques da aldeia" (Foucault, [1976] 1998: 33). A questão é que o que era parte do cotidiano da sexualidade aldeã a partir de um determinado momento tornou-se objeto não só de uma intolerância coletiva, mas de ação judiciária e de intervenção médica, 
necessitando de um exame clínico meticuloso e de toda uma elaboração teórica e científica.

Ariès ([1975] 2006) chama a atenção para o fato de que uma das leis, não escrita, de nossa moral contemporânea de hoje exige que diante das crianças os adultos se abstenham de qualquer alusão, sobretudo jocosa, a assuntos sexuais. No entanto, esse sentimento era totalmente estranho à sociedade Antiga. $\mathrm{Na}$ Antiguidade havia uma ausência de reserva diante das crianças; as crianças ouviam e viam tudo dos adultos. Eram permitidos, "com a consciência limpa e publicamente, gestos e contatos físicos que só passavam a ser proibidos quando a criança atingia a puberdade, ou seja, praticamente, o mundo dos adultos" (Ariès, [1975] 2006: 80).

Para Freud ([1905] 1995), na atualidade haverá uma ênfase no objeto, em contraponto à valorização dedicada à pulsão sexual pelos povos antigos; eles "celebravam a pulsão e se dispunham a enobrecer com ela até mesmo um objeto inferior" (Freud, [1905] 1995: 141).

Somente a partir dos séculos XVII e XVIII poderemos situar um novo núcleo de problematização: a preocupação com a sexualidade infantil e a relação entre comportamento sexual, saúde e normalidade. Apenas a partir do século XVII é que as crianças começam a ganhar um papel relevante na sociedade. Nessa época, começa a haver um compromisso em preservar a moralidade da criança, em educá-la. Nesse contexto situa-se a "descoberta da infância” (Ariès, [1975] 2006). Outro termo, "população", surge no século XVIII enquanto algo que difere do povo, uma população pela qual o governo pode medir seus fenômenos e lhes dar variáveis como: morbidade, natalidade, fecundidade, forma de alimentação, habitat, a incidência das práticas contraceptivas, etc (Foucault, [1976] 1998). E, no século XIX, o surgimento do termo sexualidade (Foucault, [1984] 1998: 9).

A junção das três terminologias (infância, sexualidade e população) abre caminho para um novo objeto de análise e alvo novo de intervenção. $\mathrm{O}$ sexo se torna questão de polícia, entra na esfera pública como algo a ser administrável. Já não se trata mais de julgar, condenar ou tolerar. É a chamada "polícia do sexo: isto é, necessidade de regular o sexo por meio de discursos úteis e públicos e não pelo rigor de uma proibição" (Foucault, [1976] 1998: 28).

Há uma mudança nos modos de convivência, há o surgimento das esferas do público e do privado. Os espaços são delimitados; e o sexo, antes enunciado em público, passa a ser assunto de foro íntimo. E, se essa transformação dos hábitos nos dá a impressão de que na antiguidade a vida era desregrada e que a modernidade traz uma repressão ao sexo, impedindo que ele faça parte do discurso das crianças e dos jovens, e, ainda, que nos adultos se dê de maneira restrita 
(preferencialmente, somente no casamento e visando a procriação), Foucault nos advertirá do contrário.

Foucault ([1976] 1998) assegura que, ao contrário do que aparenta, o que acontece nas sociedades modernas não é o desaparecimento do sexo, mas a sua inserção no discurso. Afirma que "o que é próprio das sociedades modernas não é o terem condenado o sexo a permanecer na obscuridade, mas sim o terem-se devotado a falarem dele sempre, valorizando-o como um segredo" (Foucault, [1976] 1998: 36). De modo tal que no século XIX o que se interroga é "a sexualidade das crianças, a dos loucos e dos criminosos; é o prazer dos que não amam o outro sexo" (Foucault, [1976] 1998: 39). Por outro lado, poderíamos argumentar, acerca dos dias atuais, que há um deslizamento desta concepção. No século XXI, o que vemos é que "o sexual seria associado, em prioridade, não a uma libertação, mas ao risco do abuso" (Ayon, 2001: 43).

\section{CONSIDERAÇÕES FINAIS}

Frente às constatações de que "O século XIX é o cenário do advento da psicologia como ciência do comportamento, da vida de relação" (Alberti, 2003: 121) e de que a representação de infância encontrada na atualidade é "fruto de uma invenção histórica e social" (Cirino, 2001: 20), podemos afirmar que, atualmente, o que se faz evidente nas tentativas de manejo dos casos de abuso sexual é uma pedagogização do sexo da criança, que se insere em uma dupla afirmação: quase todas as crianças se dedicam ou são suscetíveis de se dedicar a uma atividade sexual; no entanto, tal atividade sexual, sendo indevida, é considerada ao mesmo tempo natural e contra a natureza e traz consigo perigos físicos e morais, coletivos e individuais. Como nos salienta Foucault:

As crianças são definidas como seres sexuais "liminares", ao mesmo tempo aquém e já no sexo, sobre uma perigosa linha de demarcação; os pais, as famílias, os educadores, os médicos e, mais tarde, os psicólogos, todos devem se encarregar continuamente desse germe sexual precioso e arriscado, perigoso e em perigo (Foucault, [1976] 1998: 99).

Hoje "a felicidade parece estar não numa boa relação com a mãe ou no modo como cada um vivencia a própria sexualidade, mas no correto equilíbrio dos neurotransmissores secretados pelo cérebro" (Russo, 2002: 9). A classificação nosográfica e a pedagogização dos casos acabam por abolir o sujeito, seu desejo e subjetividade, 
corroborando para que ele não se responsabilize pelas escolhas que fez e faz na vida. Diante disso, podemos pensar que o discurso científico atual apresenta-se como um retrocesso em relação a Freud e chega a transformar e resumir os casos denominados de abuso sexual a uma questão epidemiológica.

Orientados por Lacan ([1958] 1998), quando considera a abordagem das psicoses, podemos dizer que encontramo-nos hoje no statu quo ante, retornamos a 1880. O que muitas abordagens fazem hoje, acerca do abuso sexual, é abolir a história, assim como fazem com o sujeito. Relativizar essa situação, questionar a pura normalização e patologização dos casos é uma contribuição que a psicanálise pode dar à abordagem do abuso sexual. Pois, no que diz respeito à interseção entre os campos da psicanálise e da ciência cartesiana, podemos afirmar que "no método analítico é o sujeito que constrói o sentido do que ele vive, na observação científica o sentido é dado do exterior" (Petitot, 1998a: 104). Diante disso, cabe ao psicanalista dar uma resposta outra, que não seja a de um agente de normalização

de quem se espera que garanta [...] a conformação dessa criança a um Ideal de Saúde mental e física: uma criança calma, sadia de corpo e de espírito, bonita, inteligente, que sabe falar, ler, escrever e contar perfeitamente, que se sai bem na escola e não apresenta nenhum problema àqueles que estão à sua volta (Hachet, 2006: 28).

A criança é idealizada e geralmente alocada em um ideal de família, através do qual o técnico seria capaz de prever e interditar as relações consideradas abusivas e violentas. Nesse contexto, Petitot (1998a) situa o surgimento da noção da "família maltratante" (famile maltraitante) que serve de base para as terapias familiares sistêmicas e psicanalíticas, dentre outras. Estas muitas vezes adotam tal noção para intervir nas famílias, delimitando os lugares e funções de cada membro - apesar de, como alerta o autor, o adulto não poder evitar que a criança seja confrontada com os efeitos de sua própria atividade psíquica e das questões que o mundo que a cerca coloca. $\mathrm{O}$ profissional, seguindo esta abordagem teórica e prática, poderá, mesmo, lhe fornecer palavras que deem sentido a esses acontecimentos, mas não poderá controlar o uso que a criança fará disso na construção de sua fantasia.

Assistimos a um crescente movimento em que sinais são relacionados e usados para a identificação de crianças vítimas de maus-tratos. Vimos que o resultado provável é a exclusão dos sujeitos, dos maltratados (vítimas), dos maltratantes (agressores), correndo-se o risco de fixá-los nesses lugares, fazendo com que acabem somente como objetos de observação e aplicação de leis. 
Por outro lado, há um terceiro elemento em jogo (Petitot, 1998b), os profissionais, que, em nome de uma "cientificidade" e do correto cumprimento das leis, também podem se desresponsabilizar por sua intervenção; agindo em nome do bem e da proteção da criança, podem não mais decidir sobre a conduta do caso de acordo com a singularidade de cada um, mas em resposta a dados estatísticos, a listas de indicadores e fatores de risco, reforçando uma dimensão policial, de vigilância administrativa, e deixando de lado a implicação subjetiva de cada um.

\section{REFERÊNCIAS}

Aded, N. L. O., Dalcin, B. L. G. S., Moraes, T. M. \& Cavalcanti, M. T. (2006). Abuso sexual em crianças e adolescentes: Revisão de 100 anos de Literatura. Revista de Psiquiatria Clinica, 33(4), 204-213.

Alberti, S. (2003). Crepúsculo da alma: a psicologia no Brasil no Século XIX. Rio de Janeiro: Contra Capa Livraria.

Amazarray, M. R. \& Koller, S. L. (1998). Alguns aspectos observados no desenvolvimento de crianças vítimas de abuso sexual. Psicologia: Reflexão e Crítica, 11(3), 559-578.

Ariès, P. (1975/2006). História social da criança e da família. Rio de Janeiro: LTC.

Ayon, P. (2001). Faut-il nier la sexualité infantile. In: Petitot, F. (org.). L'enfant, l’adulte, la loi: l'ère du soupçon (pp. 43-49). Paris: Éditions Érès.

Barbosa, G. F. (2004). O segredo de família. In: Pizá, G. (org.). A violência silenciosa do incesto (pp. 57-65). São Paulo: Impressora Oficial do Estado de São Paulo.

Brasil (1988/1999). Constituição. Brasília. Senado Federal, Subsecretaria de Edições Técnicas.

Brasil. (2002). Ministério da Saúde. Secretaria de Assistência à Saúde. Notificação de maus-tratos contra crianças e adolescentes pelos profissionais de saúde: um passo a mais na cidadania em saúde. Brasília. Ministério da Saúde.

Brasil. (1990/2005). Ministério da Educação. Estatuto da Criança e do Adolescente. Brasília: MEC, ACS.

Brasil. (2005). Ministério do Desenvolvimento Social e Combate à Fome. Secretaria Nacional de Assistência Social. Sistema Único de Assistência Social - SUAS. Norma Operacional Básica, NOB/SUA: Construindo as Bases para a Implantação do Sistema Único de Assistência Social. Brasília.

Brasil. (2006). Ministério do Desenvolvimento Social e Combate à Fome. Conselho Nacional de Assistência Social. Plano Nacional de Promoção, Proteção e Defesa do Direito de Crianças e Adolescentes à Convivência Familiar e Comunitária. Brasília. 
Calligaris, C. (1999). A moral e o abuso sexual infantil. Pulsional Revista de Psicanálise, $127,80-81$.

Cirino, O. (2001). Psicanálise e psiquiatria com crianças. Belo Horizonte: Autêntica.

Costa-Moura, F. (2003). O tratamento psicanalítico com crianças. In: Gryner, S., Ribeiro, P. M. C. M \& Oliveira, R. C. (orgs.). Lugar de palavra (pp. 126-133). Rio de Janeiro: Núcleo de Atenção à Violência (NAV).

Cromberg, R. U. (2001). Cena incestuosa: abuso e violência sexual. São Paulo: Casa do Psicólogo.

Elia, L. (2004a). O conceito de sujeito. Rio de Janeiro: Jorge Zahar Ed.

Elia, L. (2004b). Desenvolvimento, estrutura e gozo. Marraio Revista de Pesquisa de Psicanálise com Crianças, 9, 11-19.

Foucault, M. (1976/1998). História da sexualidade I: a vontade de saber. Rio de Janeiro: Graal.

Foucault, M. (1984/1998). História da sexualidade II: o uso dos prazeres. Rio de Janeiro: Graal.

Freud, S. (1905/1995). Três ensaios sobre a sexualidade. Obras completas, ESB, v. VII. Rio de Janeiro: Imago.

Goldfeder, M. F. F. (2001). A relação esquecida: a mãe nos bastidores do abuso sexual entre pai e filha. Pulsional Revista de Psicanálise, 138, 16-23.

Hachet, A. (2006). Entre prevenir e normalizar, que lugar terá o sofrimento da criança? Agora, 1, 27-34.

Junqueira, M. F. P. S. (1999). Abuso sexual da criança, desamparo e superego: uma reflexão. Cadernos de Psicanálise, 21(13), 55-63.

Lacan, J. (1954-1955/1985). O seminário, livro 2: o eu na teoria de Freud e na técnica da psicanálise. Rio de Janeiro: Jorge Zahar Ed.

Lacan, J. (1958/1998). De uma questão preliminar a todo tratamento possível da psicose. In: Escritos (pp. 531-590). Rio de Janeiro: Jorge Zahar Ed.

Lacan, J. (1976). Da estrutura como intromistura de um pré-requisito de alteridade e um sujeito qualquer. In: Macksey, R. \& Donato, E. (orgs.). A controvérsia estruturalista (pp. 198-229). São Paulo: Cultrix.

Magalhães, A. P. (2005). Abuso sexual incestuoso: um tema centrado na criança e na família. Rio de Janeiro: Letra Capital.

Petitot, F. (1998a). La confusion des langues: le discours “psy”. In: Gavarini, L. \& Petitot, F. La fabrique de l'enfant maltraité: un nouveau regard sur l'enfant et la famille (pp. 101113). Paris: Editions Érès.

Petitot, F. (1998b). Qu'est-ce qu'un enfant qui ne serait pas em danger? In: Gavarini, L. \& Petitot, F. La fabrique de l'enfant maltraité: un nouveau regard sur l'enfant et la famille (pp. 29-43). Paris: Éditions Érès. 
Ribeiro, P. M. C. M \& Gryner, S. (2003). Considerações sobre a exploração sexual comercial: de que risco se trata? In: Gryner, S., Ribeiro, P. M. C. M. \& Oliveira, R. C. (orgs.). Lugar de palavra (pp. 74-79). Rio de Janeiro: Núcleo de Atenção à Violência (NAV). Russo, J. (2002). O mundo PSI no Brasil. Rio de Janeiro: Jorge Zahar Ed.

\section{Notas}

1 Este artigo é parte da dissertação de Mestrado de Pedro Moacyr Chagas Brandão Junior, defendida em 2008 no Instituto de Psicologia da Universidade do Estado do Rio de Janeiro (UERJ) dentro do Programa de Pós-graduação em Psicanálise, com o título o "Sujeito abusado da psicanálise”.

2 Ver, por exemplo, Norma Operacional Básica do Sistema Único de Assistência Social (NOB/SUAS) e Plano Nacional de Promoção, Proteção e Defesa do Direito de Crianças e Adolescentes à Convivência Familiar e Comunitária (Brasil, 2005).

3 Ver cartilha publicada em 2002 pelo Ministério da Saúde: Notificação de maus-tratos contra crianças e adolescentes pelos profissionais de saúde: um passo a mais na cidadania em saúde.

Recebido em 25 de agosto de 2008 Aceito para publicação em 06 de maio de 2010 